\title{
Effect of Perceived Social Support Components on Happiness of Physical Veterans' Wives in Zanjan, Iran
}

\section{ART ICLE INF O}

\section{Article Type}

Descriptive Study

\section{Authors}

Shams N. ${ }^{1} M S c$,

Payami Bousari M. ${ }^{* 1} P h D$,

Heyadari Some A. ${ }^{2} M S c$,

Fallah R. ${ }^{3} P h D$

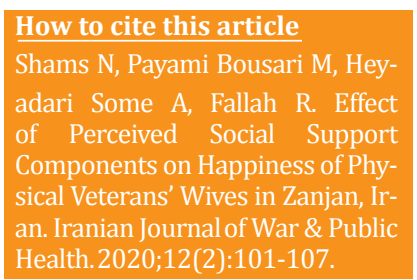

${ }^{1}$ Department of Nursing Health, School of Nursing and Midwifery, Zanjan University of Medical Sciences, Zanjan, Iran

${ }^{2}$ Janbazan Medical and Engineering Research Center (JMERC), Tehran, Iran

${ }^{3}$ Department of Biological Statistics and Epidemiology, School of Medicine, Zanjan University of Medical Sciences, Zanjan, Iran

\section{*Correspondence}

Address: School of Nursing and Midwifery, Centeral Capmus of Zanjan University of Medical Sciences, Dr Sobouti (Gavazang) Blvd., Zanjan, Iran. Postal Code: 4513956113. Phone: +98 (24) 33148318

Fax: +98 (24) 33148319 mitra_payami@yahoo.com

\section{Article History}

Received: March 09, 2020

Accepted: May 14, 2020

ePublished: June 17, 2020

\section{A B S T R A C T}

Aims This study investigated the effect of perceived social support on the happiness of the wives of Zanjan physical veterans.

Instruments \& Methods This is a descriptive correlational study. 188 wives of physical veterans with a percentage of $40 \%$ and above were selected by simple random sampling. Data were collected through Oxford and Zimet questionnaires and analyzed by multivariate regression in SPSS 25 software.

Findings The age group of 45 to 54 years, with $60.6 \%$, had the highest frequency. $55.9 \%$ of veterans' wives' happiness level was high, $41 \%$ moderate, and $3.2 \%$ low. Among the happiness components, the lowest mean was related to the aesthetic (1.85) and the highest to self-efficacy (2.27). 78.72\% of veterans' wives reported high perceived social support, $15.50 \%$ moderate, and 5.85\% low. The highest averages were obtained from family (4.02), community (3.92), and friends (2.91), respectively. There was a significant relationship between the components of happiness and perceived social support $(\mathrm{p}<0.05)$. The results showed that the correlation coefficient of social support components with happiness $(M R=0.443$ and $R S=0.96)$ was significant $(p<0.00)$, and $19.6 \%$ of the variance of happiness is explained by the dimensions of perceived social support Among the three types of social support, only family support was predictive of happiness $(\mathrm{p}<0.00)$.

Conclusion Family support plays a major role in the happiness of physical veterans' wives.

Keywords Social Support; Happiness; Wives; Families of Veterans

\section{I T A T I O N L I N K S}

[1] The effect of training conflict resolution on ... [2] Coping, affective distress, and psychosocial ... [3] Sociodemographic factors and their influence ... [4] Family burden and quality ... [5] Evaluation of epidemiology of chronic disease ... [6] Comprehensive law on services to ... [7] Relationship between religious beliefs and stress ... [8] Comparison of life expectancy, quality ... [9] Effect Of Training Spiritual Intelligence ... [10] Does positive affect influence ... [11] Relationship between resilience and satisfaction ... [12] A longitudinal experimental study ... [13] The relationship between hardiness and happiness ... [14] Association of depressive symptoms and ... [15] Relationship between quality of life and social ... [16] Stress coping strategies and social support ... [17] Relationship between social support with ... [18] Psychometric properties of the Multidimensional ... [19] The Relationship between perceived social support ... [20] Confirmatory factor analysis of the multidimensional ... [21] Evaluation of effectiveness of training ... [22] Measurement invariance of post traumatic ... [23] Investigating the association between ... [24] Effective factors on level of morale, happiness ... [25] A preliminary evaluation of the validity ... [26] Internet and communication: Perceived ... [27] The analysis of psychosocial factors ... [28] Relationship between social support ... [29] Correlation of social support with social health ... [30] The Impact of Social Support on Quality ... [31] An interactive study of the effect of social economic ... [32] Stressed and happy? Investigating ... [33] The role of social support in predicting ... [34] A study of the effects of social support elements ... [35] The Relationship Between Social Support ... [36] Factor affecting happiness among nursing students ... [37] Social support and happiness in immigrant ... 
بيمارىهاى مزمن مىتواند جنبههاي مختلف زندكى اين افراد را

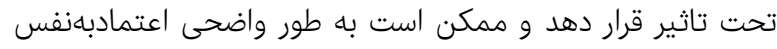

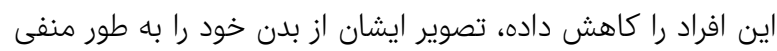

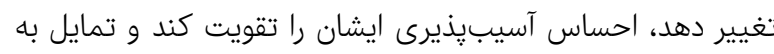

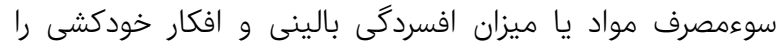

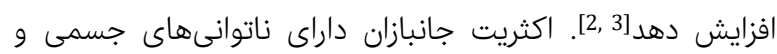
حركتى و اختلالات روانشناختى نظير اضطراب، افسردگى، اختئل اختلال

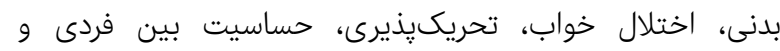

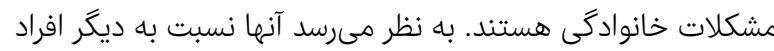

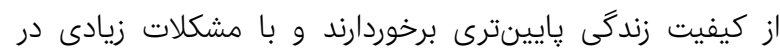

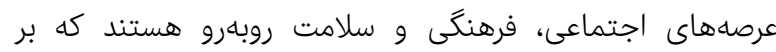

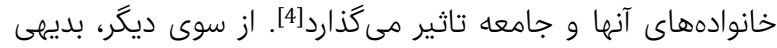

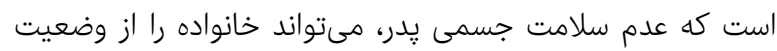

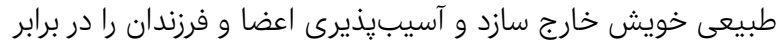

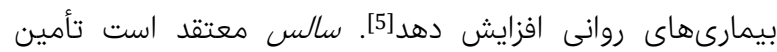

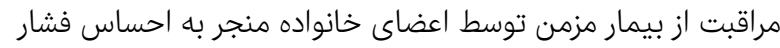

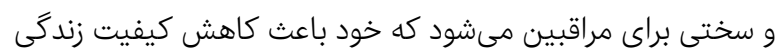

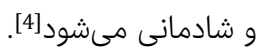

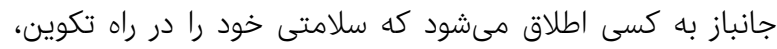

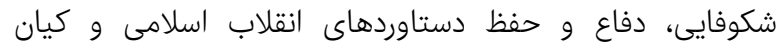

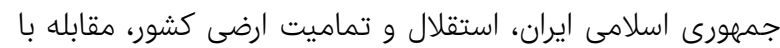

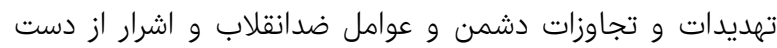

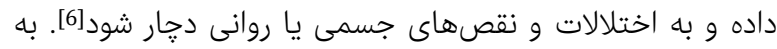
طور معمول كنارآمدن با مشكلات جسمى و روانى جانبازان، معمولا لناليا

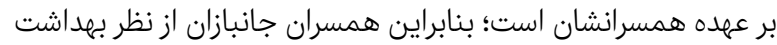

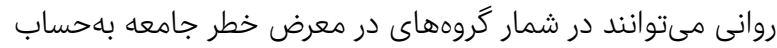

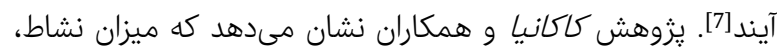

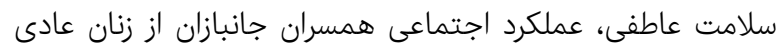

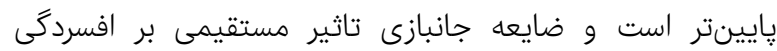

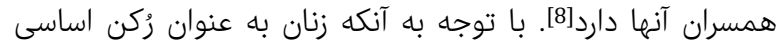

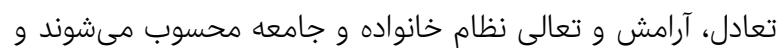

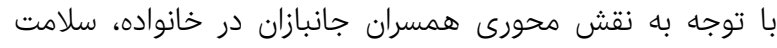

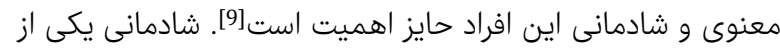
عواملى است كه ارتباط مستقيم با وضعيت سلائ إمتادي، امنيت،

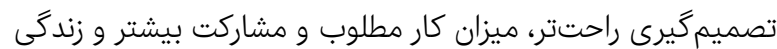

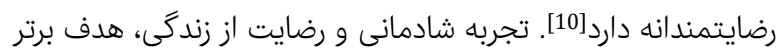

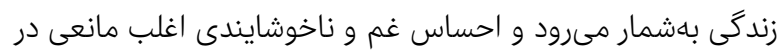
راه انجام وظايف فرد شمرده مى شود [11].].

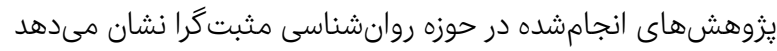

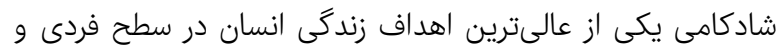

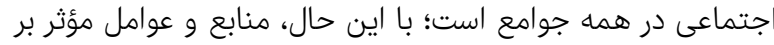

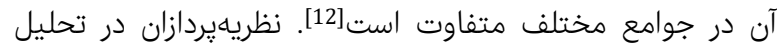

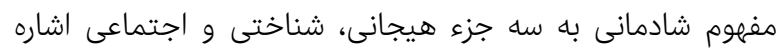
نمودهاند؛ "جزء هيجانى" كه فرد شادكام از نظر خلقى، شاد هاد و
تاثير مؤلفههاى حمايت اجتماعى دركشده بران شادمانى در همسران جانبازان جسمى زنجان

\author{
MSc Mرين شمس برون \\ كَروه يرستارى، دانشكده بِرستارى و مامايى، دانشكاه علوم يزشكى زنجان، زنجان، \\ ايران

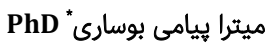

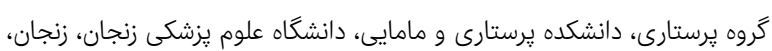

ايران

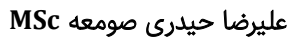

مركز تحقيقات مهندسى و علوم بزنشكى جانبازان، تهران، ايران

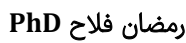

كَروه آمار زيستى و إيدميولوزى، دانشكده بزنشى، دانشكاه علوم يزشكى زنجان،

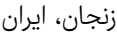

جكيده

هدف: يزوهش حاضر با هدف بررسى تاثير حمايت اجتماعى دركشده بر شادمانى

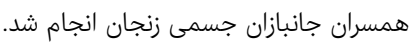

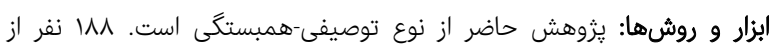

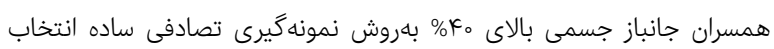

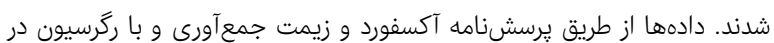
SPSS 25

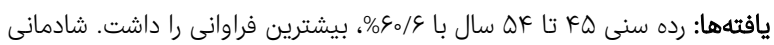

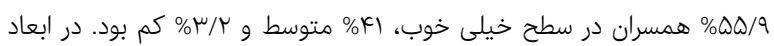

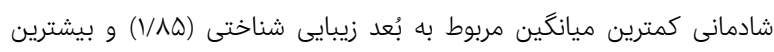

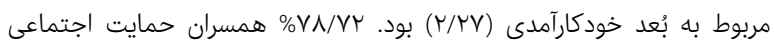

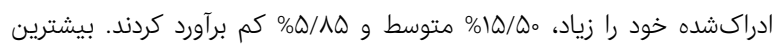

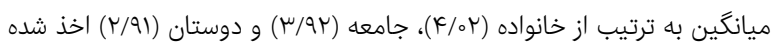

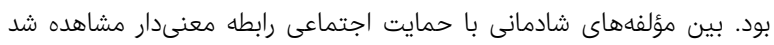

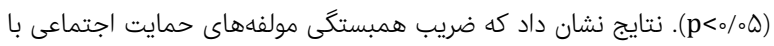

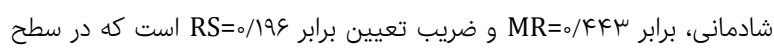

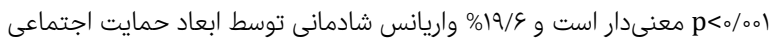

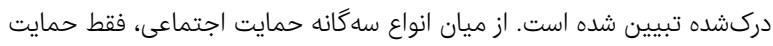

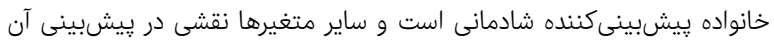

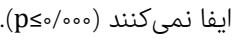
نتيجهكيرى: حمايت اجتماعى دركشده در همسران جانبازان منجر به افزايش

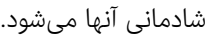
كليدوازهها: حمايت اجتماعى، شادمانى، همسران، خانواده جانبازان

تاريخ دريافت: تاريخ يذيرش تاريخ קيذيرش: تاريخ دريافت: "نويسنده مسئول: mitra_payami@yahoo.com

مقدمه

جنگ يِيامدهاى ناكوارى براى كشورها، رزمندكان و خانوادههاى آنها

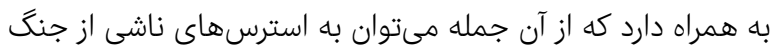

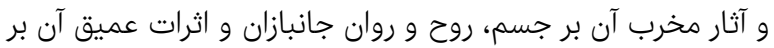

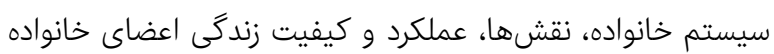
اشاره كرد[1]. قطع عضو و مشكل جسمى در جانبازان مانند ساير إناي 


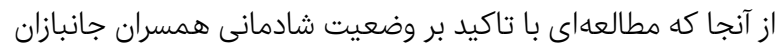

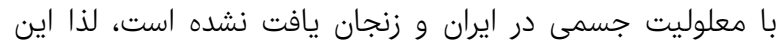
يزوهش با هدف تعيين رابطه بين وضعيت شادمانى با حمايت ائران اجتماعى دركشده در همسران جانبازان جسمى شهر زنجان انجام

\section{ابزار و روشها}

اين يزوهش از نوع توصيفى-همبستخى است. جامعه آمارى

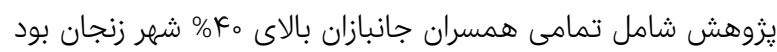

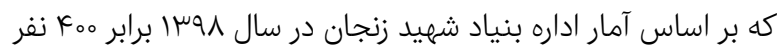

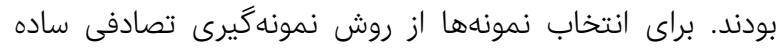

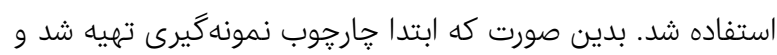

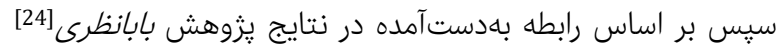

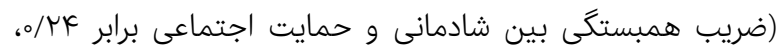

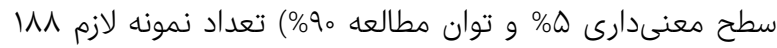
مورد تعيين شد و به صورت تصادفى از ليست تهيهاهده انتخاب و و به عنوان نمونه يزووهش در اين مطالعه وارد شدند. معيارهاى ورود

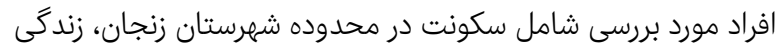

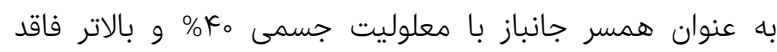

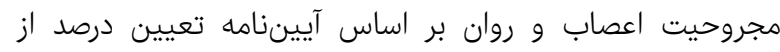

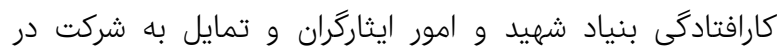

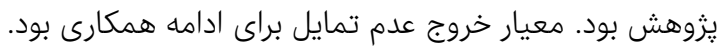

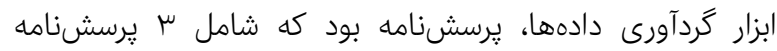
اطلاعات جمعيتشناختى، يرسش نرسامه شادمانى آكسفورد (كه داراى

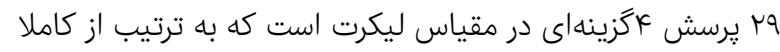

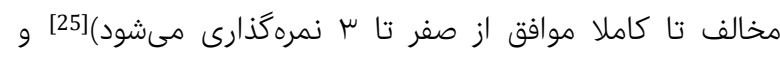

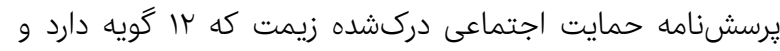

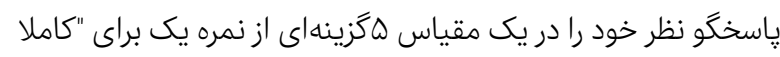

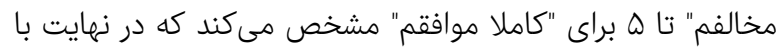
ادغام طيف كاملا مخالف و مخالف (نمره يك)، نظرى ندارئ (نارم (نمره

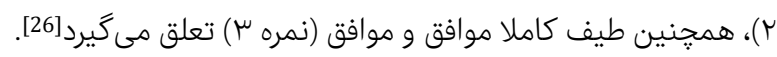

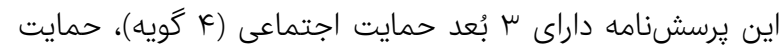

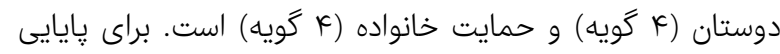

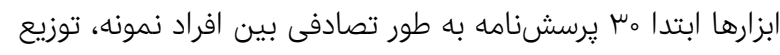

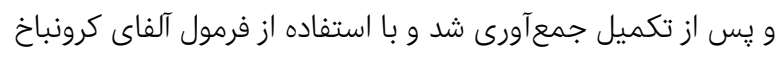

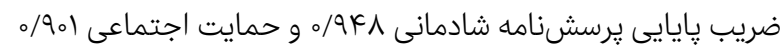

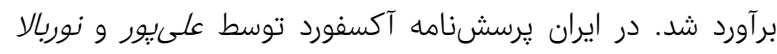

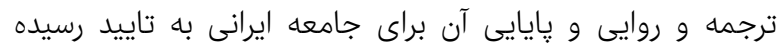

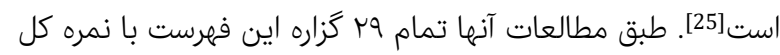

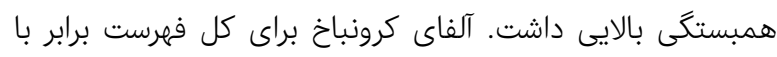

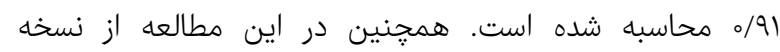

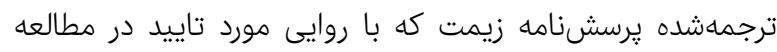
سليمى و همكاران [26] بكار رفته، استفاده شد.
خوشحال است؛ "جزء شناختى" كه باعث مىشود فرد شادكام اطلاعات را بهروش خاصى يردازش كرده، مورد تعبير و تفسير قرار

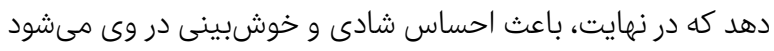

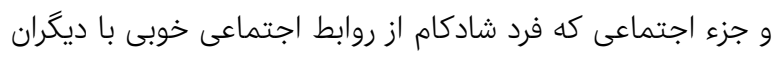

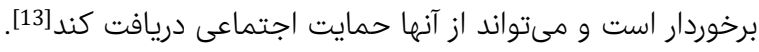

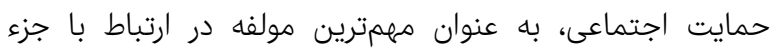

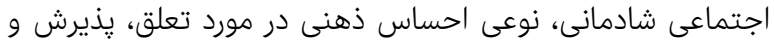

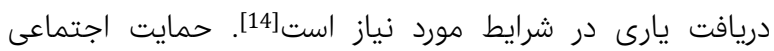

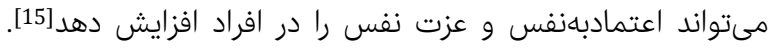

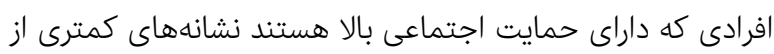

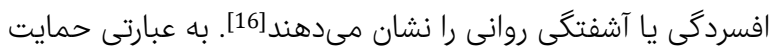

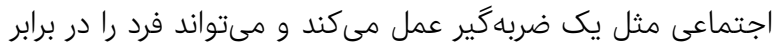

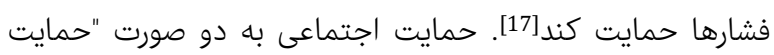

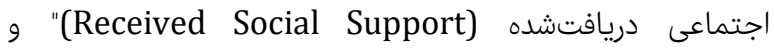
"دركشده (Perceived Social Support)" مورد مطالعه قرار

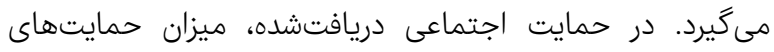

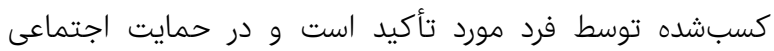

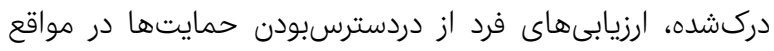

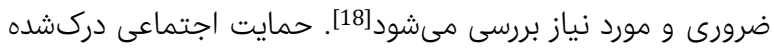

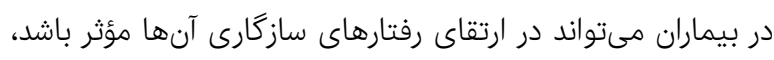

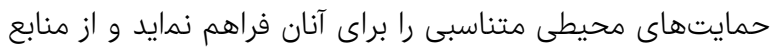

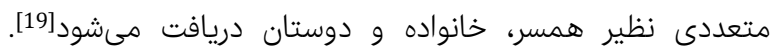
نظريهيردازان اين حوزه بر اين باورند كه تمامى روابطى كه فردي فرد باني

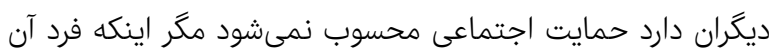

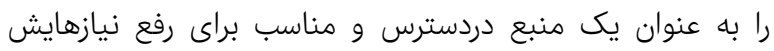

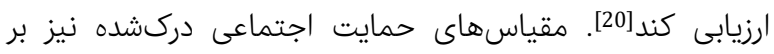

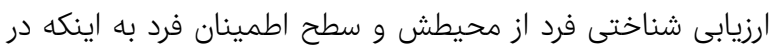

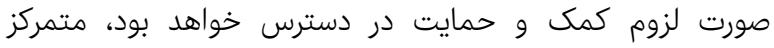

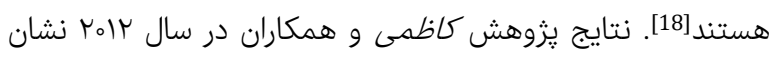

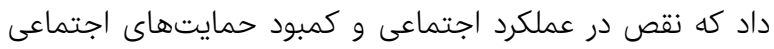

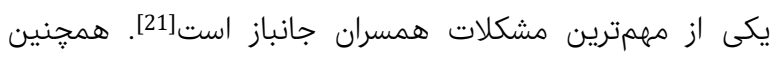

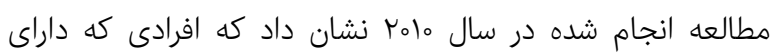
حمايتهاى اجتماعى بالا هستند در رويارويى با رخدادهاى داد فشارآ دارور

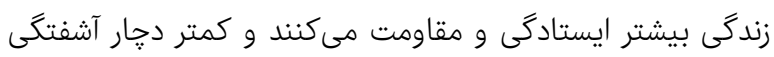

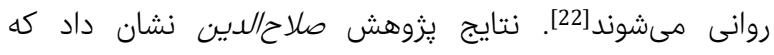
حمايتهاى اجتماعى از سوى افراد كليدى تيم درائ درانى

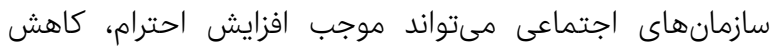

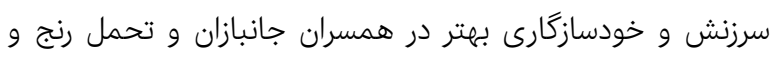
تبنش در زندگى آنان شود [23].

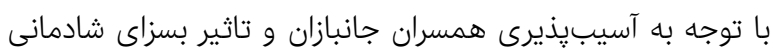

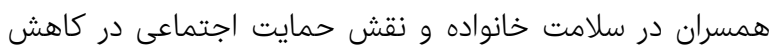

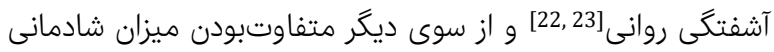

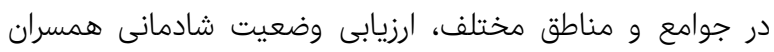
جانباز و ارتباط آن با حمايت اجتماعى ادراكشده آنان ضروريست. 
نتايج آزمون ضريب همبستگى ييرسون بيانكً رابطه مثبت و متوسط

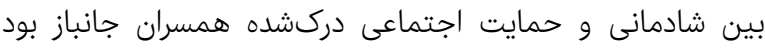
. $(r=0 / 4) ! p<0 / 0)$

بر اساس نتايج حاصل از تحليل رگرسيون جندگًانه و با استفاده از روش ورود، ضريب همبستگى جندگانه براى تركيب خطى إنى ابعاد

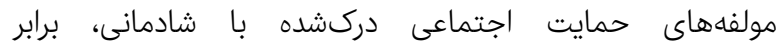
و ضريب تعيين برابر RR=。/KF

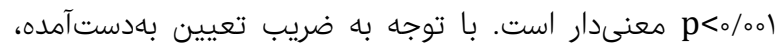
مشخص شده است كه حدود 19/9\% واريانس متغير شادمانى توسط له متغيرهاى ييشبين ابعاد حمايت اجتماعى دركشده (حمايت

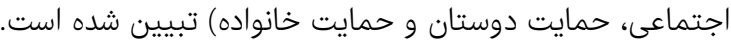

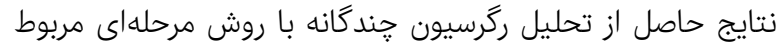
به ابعاد حمايت اجتماعى دركشده و شادمانى همسران جانبازان نشان داد كه از بين انواع حمايت اجتماعى دركشده، حمايت دماني

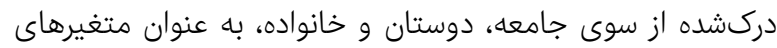

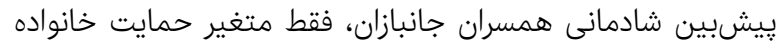

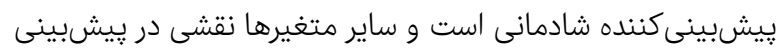

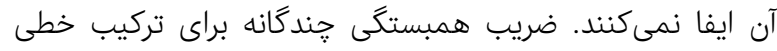

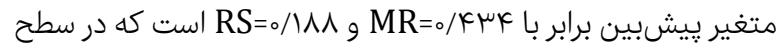

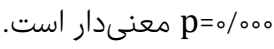

بحث

يافته هاى يزوهش نشان مىدهد كه شادمانى جانبازان در سطح خيلى خوب قرار دارد و تننها ب/ش\% آنها در سطح

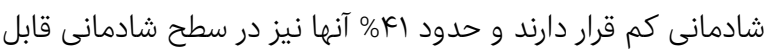

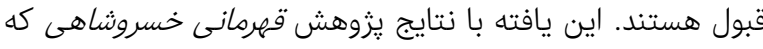

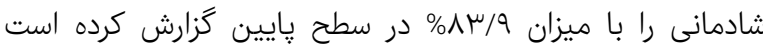

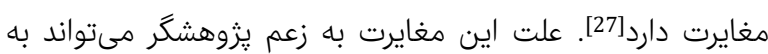

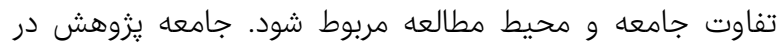
مطالعه قهرمانى خسروشاهى را جوانان شهر تهران تشكيل مئ مدادند مراند كه از لحاظ شرايط سنى جنسى و تاهل با همسران جانباز متفاوت

يافتههاى يزوهش حاضر نشان داد كه سطح حمايت اجتماعى

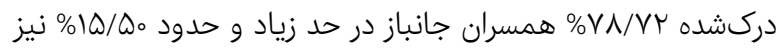
در حد متوسط بود. اين يافته با نتيجه نتايج يزوهش قهردان

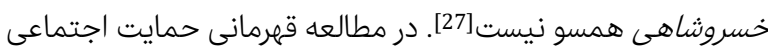

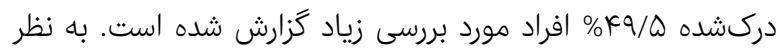

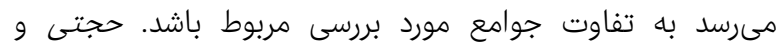
همكاران و صالح و همكاران در مطالعه خود ميزان حمايت همسران

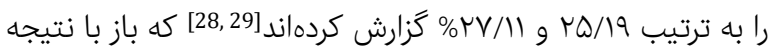
يثروهش حاضر يكسان نيست. محدوديت سنى، ابزار متفاوت و تغيير

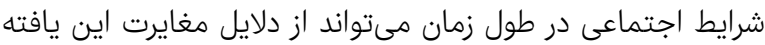
باشد. نتايج اين مطالعه نشان داد كه بين شادمانى و حمايت دركشده

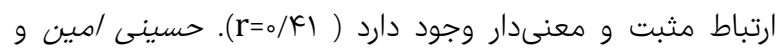
دوره rا، شماره r، بهار 99سו

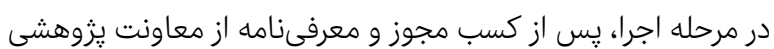

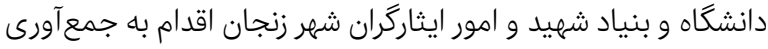
اطلاعات شد. بدين منظور با هماهنگى بنياد شهيد و امور ايثارگران

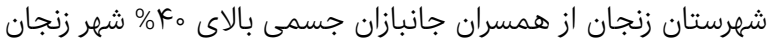

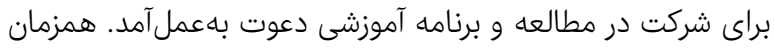

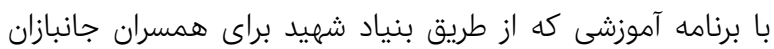

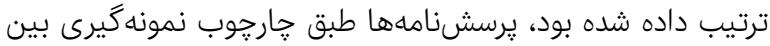
افرادى كه به عنوان نمونه انتخاب شده بودند، بعد از توضيح هدف برد

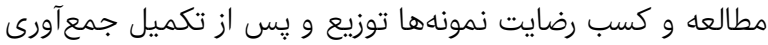

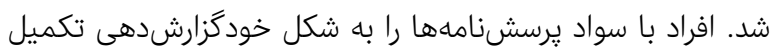

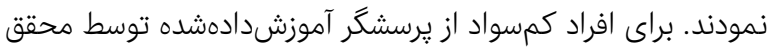

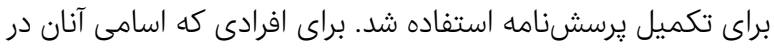

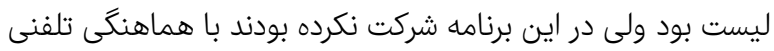

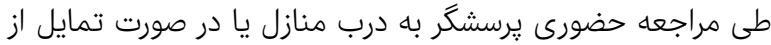

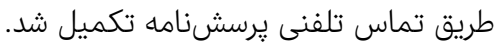

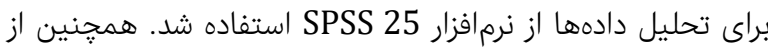
آمار توصيفى كه شامل فراوانى و درصدها بود، استفاده شد و درار درار

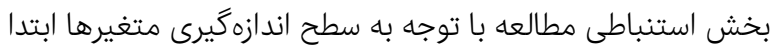

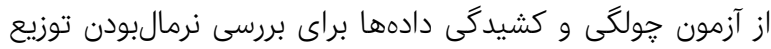

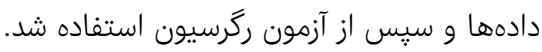

\section{يافتهها}

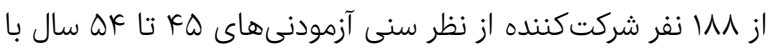

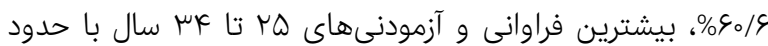

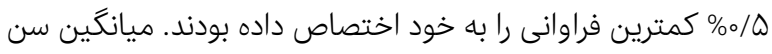
همسران جانبازان مورد بررسى

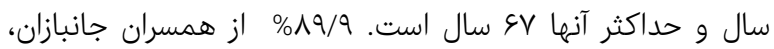

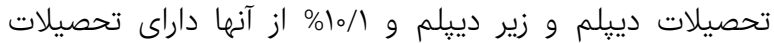

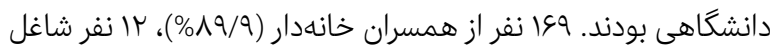

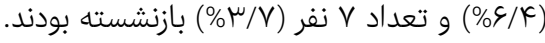

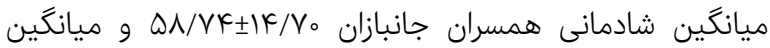

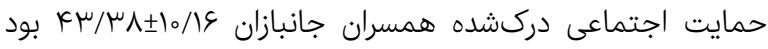

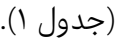

جدول () سطوح و درصد شادمانى و حمايت اجتماعى دركشده در همسران

\begin{tabular}{|c|c|c|}
\hline درصد & فراوانى & سطوح \\
\hline & & شادمانى \\
\hline$\mu / r$ & 4 & كم (o-r人) \\
\hline $\mathrm{kY} / \mathrm{o}$ & VV & ثابل قبول (rq-هV) \\
\hline$\triangle Q / ৭$ & 1.0 & 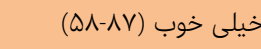 \\
\hline \multirow[t]{2}{*}{100} & $M \Lambda$ & كل \\
\hline & & حمايت اجتماعى دركشده \\
\hline$\Delta / 9$ & 11 & كم (o-MK) \\
\hline $10 / 4$ & rq & متوسط (ع) \\
\hline$\wedge \mathrm{V} / \mathrm{V}$ & lkF & رياد (ץ و بالاتر) \\
\hline 100 & $M \Lambda$ & كل \\
\hline
\end{tabular}

فصلنامه علمى- يُوهشى طب جانباز 


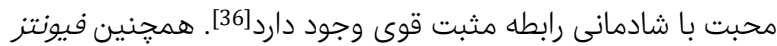

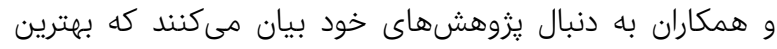
ييشبينى كنندهاى شادى، حمايت عاطفى از خانواده و حمايت

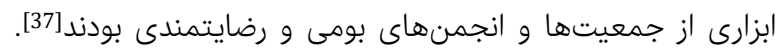

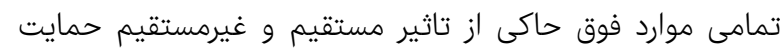
اجتماعى دركشده بر شادمانى هستند.

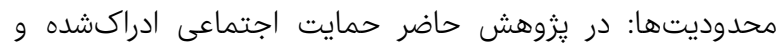

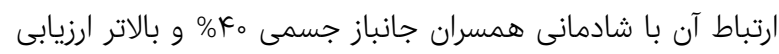

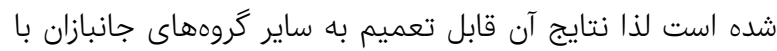
درصد يايينتر نيست.

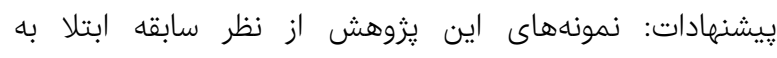

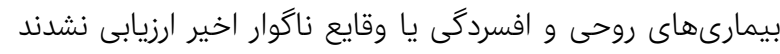

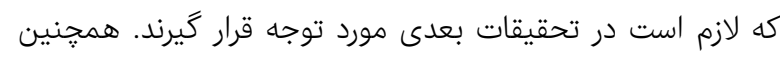
توصيه مىشود تا برنامهريزىهاى آتى به منظور تأكيد بر استفاده از توريهات

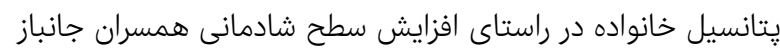

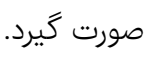

\section{نتيجه خيرى}

حمايت اجتماعى دركشده در همسران جانبازان منجر به افزايش

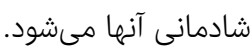

تشكر و قدردانى: از معاونت يزوهشى دانشگاه علوم يزشكى زنجان،

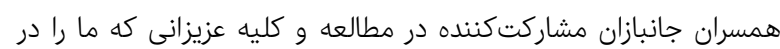
انجام اين يزوهش يارى رساندند كمال تشكر را داريم.

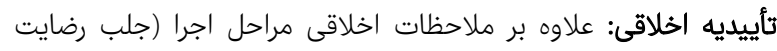

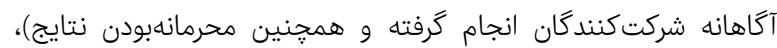

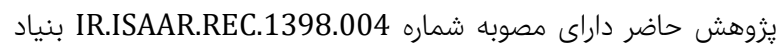

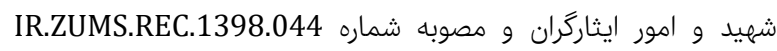

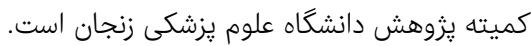

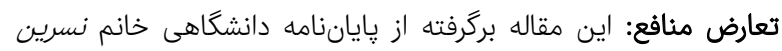

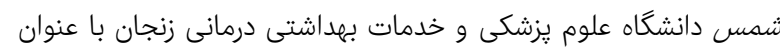

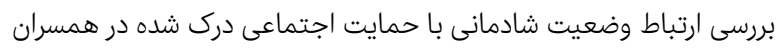

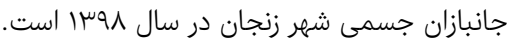

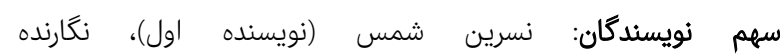

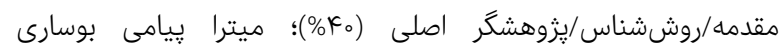

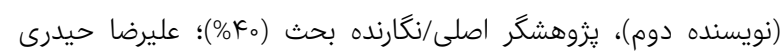

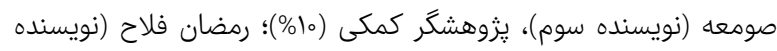

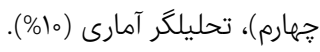

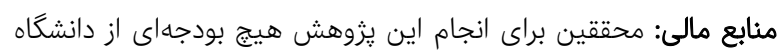

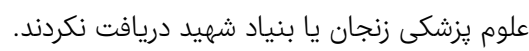

\section{منابع}

1- Parandeh A, Sirati M, Khaghanizadeh M, KarimiZarchi A. The effect of training conflict resolution on quality of life's on spouses of war veterans post traumattic stress disorder. J Mil Med. 2006;8(1):45-51. [Persian]
همكاران در مطالعهاى كه روى زنان شهر تهران انجام داده بودند به اين نتيجه رسيدند كه با افزايش حمايت اجتماعى، شادمانى نيز

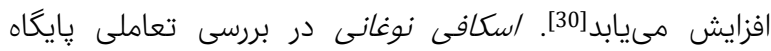

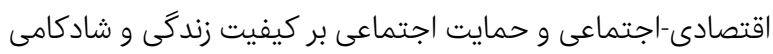

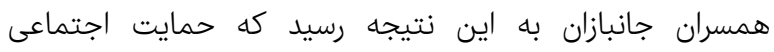

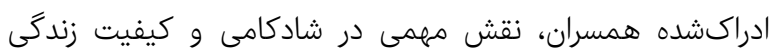
همسران جانبازان ايفا مىكند [31].

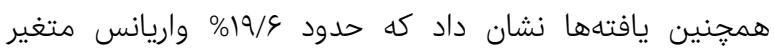

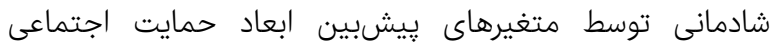
دركشده يعنى حمايت جامعه، حمايت دوستان و حمايت خانواده

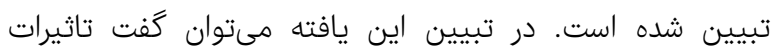
حفاظتى حمايت اجتماعى، ممكن است نتيجه جنين لندين فرآيند باشند.

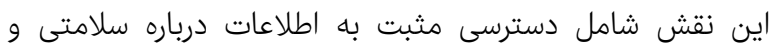

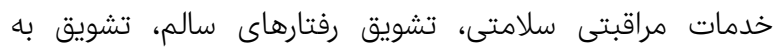

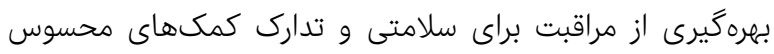

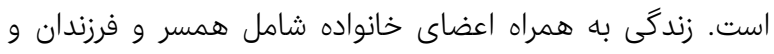
توجهات و حمايتهاى مادى و عاطفى كه فرد از اعضاى خانواده

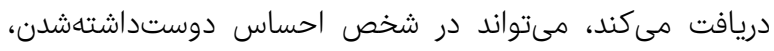

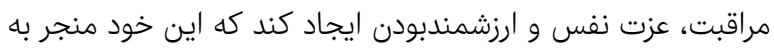

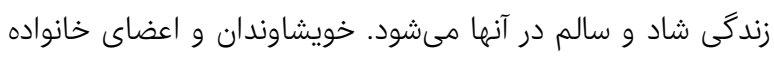

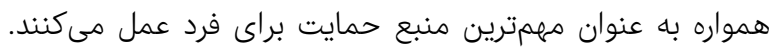

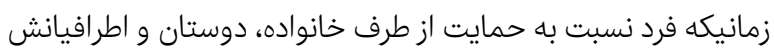

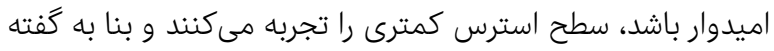

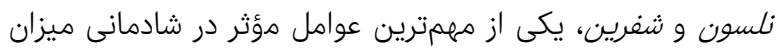

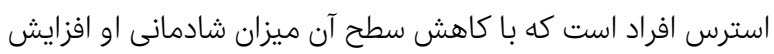

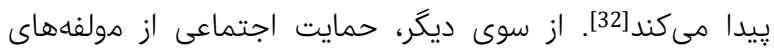

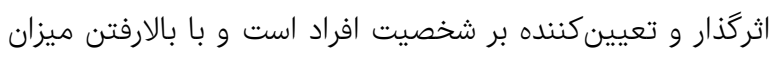

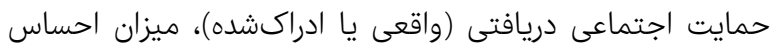

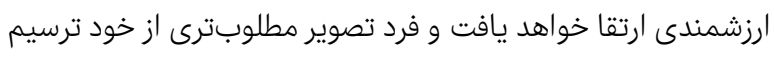
خواهد كرد، نتيجه كلى اين وضعيت افزايش شادمانى و رضايت در در

$$
\text { زندگى است] [33]. }
$$

يافته اين يزوهش نشان مى اسدهد كه مولفههاى حمايت اجتماعى

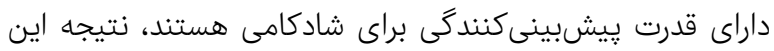

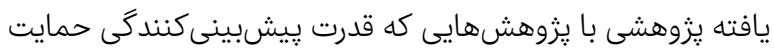

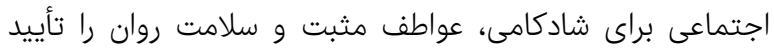

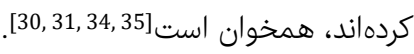

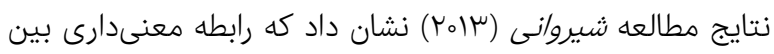

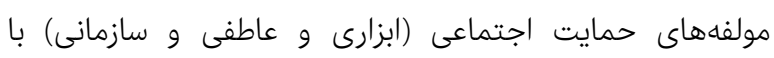
شادكامى اجتماعى وجود دارد[34]. كيخسروى بيكز/ده و همكاران در إنيت

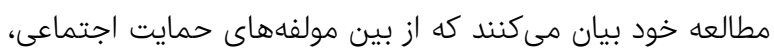

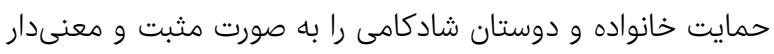

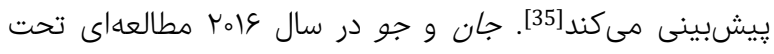

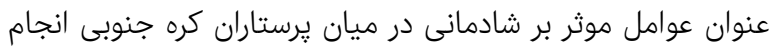

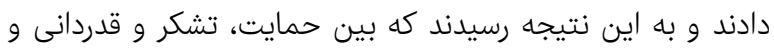


19- Tol A, Majlessi F, Rahimi A, Shojaeizadeh D, Mohebbi B. The Relationship between perceived social support from family and diabetes control among patients with diabetes type 1 and type 2. J Diabetes Metab Disord. 2011;10:21.

20- Clara IP, Cox BJ, Enns MW, Murray LT, Torgrudc LJ. Confirmatory factor analysis of the multidimensional scale of perceived social support in clinically distressed and student samples. J Pers Assess. 2003;81(3):265-70.

21- Kazemi AS, Banijamali SA, Ahadi H, Farrokhi N. Evaluation of effectiveness of training cognitive behavioral strategies in the secondary traumatic stress disorder (STSD) symptoms and psychological problems among devotees' wives with chronic PTSD due to war. J Med Sci. 2012;22(2):122-9. [Persian]

22- Mansfield AJ, Williams J, Hourani LL, Babeu LA. Measurement invariance of post traumatic stress disorder symptoms among U.S. military personnel. J Trauma Stress. 2010;23(1):91-9.

23- Salahaldin S. Investigating the association between social support and social health among psychiatric veterans wives in tehran. J Soc Mork. 2014;3(7):34-43. [Persian]

24- Babanazari L, Taghavi MR. Effective factors on level of morale, happiness and life expectancy in families of soldiers killed in war and veterans' families; case study of Fars province. Iran J Isaar Stud. 2020;1(2):83-92. [Persian]

25- Alipoor A, Noorbala AA. A preliminary evaluation of the validity and reliability of the Oxford happiness questionnaire in students in the universities of Tehran. Iran J Psychiatry Clin Psychol. 1999;5(1):55-66. [Persian] 26- Salimi A, Joukar B, Nikpour R. Internet and communication: Perceived social support and loneliness as antecedent variables. Psychol Stud. 2009;5(3):81-102. [Persian]

27- Ghahremani Khosroshahi F. The analysis of psychosocial factors affecting on the feeling of happiness among youths (18-29) of Tehran [Dissertation]. Mazandaran: University of Mazandaran Faculty of social and Human Science; 2012. [Persian]

28- Hojjati H, Ebadi A, Zare K, Akoundzadeh G, Alostani J, Nouhi E. Relationship between social support and quality of life dimensions of spouses of veterans with posttraumatic stress disorder. Mil Caring Sci. 2017;4(2):87-94. [Persian]

29- Saleh S, Zahedi Asl M. Correlation of social support with social health of psychiatry veterans wives. Iran J War Public Health. 2014;6(5):201-6. [Persian]

30- Hoseini Amin SN, Nami M, Zare Mohmood Abadi MA. The Impact of Social Support on Quality of Life for Women in Tehran. Second International Conference on Management, Accounting, Economics and Social Sciences. Hamedan: Islamic Azad University; 2019. [Persian]

31- Eskafi Noghani M. An interactive study of the effect of social economic status and support on life quality and mental happiness of veterans' wives with post-traumatic stress disorder in Mashhad. J Mil Med. 2017;19(3):27481. [Persian]

32- Schiffrin HH, Nelson SK. Stressed and happy? Investigating the relationship between happiness and perceived stress. J Happiness Stud. 2010;11(1):33-9.

33- Ghasemi S, Pooladi Reyshari A, Ghasemi K, Ghasemi 0. The role of social support in predicting students' selfesteem and happiness. World Congress on Management of Mental Health and Psychological Sciences. Shiraz: 2- Desmond DM. Coping, affective distress, and psychosocial adjustment among people with traumatic upper limb amputations. J Psychosom Res. 2007;62(1):15-21.

3- Badura-Brzoza K, Matysiakiewicz J, Piegza M, Rycerski W, Niedziela U, Hese R. Sociodemographic factors and their influence on anxiety and depression in patients after limb amputation. Psychiatr Pol. 2006;40(2):335-45.

4- Sales E. Family burden and quality of life. Qual Life Res. 2003;12(1):33-41.

5- Nejati V, Ahmadi K. Evaluation of epidemiology of chronic disease in Iranian psychiatric veterans. Iran J War Public Health. 2010;2(4):8-12. [Persian]

6- Islamic Parliament Research Center of the Islamic Republic of Iran. Comprehensive law on services to veterans. Tehran: Islamic Parliament Research Center of the Islamic Republic of Iran; 2007 [Unknown Cited]. Available

from: https://rc.majlis.ir/fa/law/show/840522. [Persian] 7- Moghtader L. Relationship between religious beliefs and stress coping strategies in psychological resilience and marital satisfaction of veterans wives. J Guilan Uni Med Sci. 2017;26(103):37-45. [Persian]

8- Kakania M, Naderi R. Comparison of life expectancy, quality of life and marital satisfaction among veterans of war veterans and normal people. First International Conference on Management Patterns in the Progressive Era. Tehran: Islamic Azad University; 2017. [Persian] 9- Haditabar H, Navabinejad S, Ahghar G. Effect Of Training Spiritual Intelligence On Quality Of Life Among Veteran Spouses. Iran J War Public Health. 2012;4(2):111. [Persian]

10- Pressman SD, Cohen S. Does positive affect influence health?. Psychological bulletin. 2005;131(6):925-71.

11- Khalatbari J, Bahari S. Relationship between resilience and satisfaction of life. J Educ Psychol. 2010;1(2):83-94. [Persian]

12- Boehm JK, Lyubomirsky S, Sheldon KM. A longitudinal experimental study comparing the effectiveness of happiness-enhancing strategies in Anglo Americans and Asian Americans. Cogn Emot. 2011;25(7):1263-72.

13- Aminpoor H, Naghadeh SA. The relationship between hardiness and happiness in students of Payame Noor University. J Educ Manag Stud. 2014;4(2):293-7.

14- Wu CY, Prosser RA, Taylor JY. Association of depressive symptoms and social support on blood pressure among urban African American women and girls. J Am Acad Nurs Pract. 2010;22(12):694-704.

15- Heidarzadeh M, Ghahremanian A, Hagigat A, Yoosefi E. Relationship between quality of life and social support in stroke patients. Iran J Nurs. 2009;22(59):23-32. [Persian]

16- Ebrahimi A, Bolhari J, Zolfaghari F. Stress coping strategies and social support in depressive veterans with spinal cord injury. Iran J Psychiatry Clin Psychol. 2002;8(2):40-8. [Persian]

17- Abdollahzade Rafi M, Hassanzadeh M, Ahmadi SH, Taheri M, Hosseini M. Relationship between social support with depression and anxiety during third trimester pregnancy. Iran J Nurs Res. 2012;7(26):1-10. [Persian]

18- Bruwer B, Emsley R, Kidd M, Lochner C, Seedat S. Psychometric properties of the Multidimensional Scale of Perceived Social Support in youth. Compr Psychiatry. 2008;49(2):195-201. 
1.V تـاثير مؤلفهاى حمايت اجتماعى دركشه بر شادمانى در همسران جانبازان جسمى زنجان

With Happiness Among Home-Dwelling Older Adults in Shiraz. Salmand. 2015;10(2):172-9. [Persian]

36- Jun W, Jo M. Factor affecting happiness among nursing students in South Korea. J Psychiatr Ment Health Nurs. 2016;23(6-7):419-26.

37- Dominguez-Fuentes JM, Hombrados-Mendieta MI. Social support and happiness in immigrant women in Spain. Psychol Rep. 2012;110(3):977-90.
Shiraz University; 2017. [Persian]

34- Shirvani FA. A study of the effects of social support elements from retired elders om their social happiness (Case study,retirement association of the Islamic republic of Iran) [Dissertation]. Tehran: Islamic Azad University; 2013. [Persian]

35- Keykhosravi Beygzadeh Z, Rezaei A, Khalouei Y. The Relationship Between Social Support and Life Satisfaction 